\title{
Complex Multiplexing of Reward-Cue- and Licking- Movement-Related Activity in Single Midline Thalamus Neurons
}

\author{
Yuhong Li, @Christoph Lindemann, Matthew J. Goddard, and $\odot$ Brian I. Hyland \\ Department of Physiology, Otago School of Medical Sciences, Brain Health Research Centre, University of Otago, and the Brain Research New Zealand \\ Centre of Research Excellence, Dunedin 9054, New Zealand
}

Midline thalamus is implicated in linking visceral and exteroceptive sensory information with behavior. However, whether neuronal activity is modulated with temporal precision by cues and actions in real time is unknown. Using single-neuron recording and a Pavlovian visual-cue/liquid-reward association task in rats, we discovered phasic responses to sensory cues, appropriately timed to modify information processing in output targets, as well as tonic modulations within and between trials that were differentially reward modulated, which may have distinct arousal functions. Many of the cue-responsive neurons also responded to repetitive licks, consistent with sensorimotor integration. Further, some lick-related neurons were activated only by the first rewarded lick and only if that lick were also part of a conditioned response sequence initiated earlier, consistent with binding action decisions to their ensuing outcome. This rich repertoire of responses provides electrophysiological evidence for midline thalamus as a site of complex information integration for reward-mediated behavior.

Key words: action-outcome binding; conditioned response; paraventricular thalamus; reward; rhythmic motor pattern; single neuron

\section{Significance Statement}

Disparate brain circuits are involved in sensation, movement, and reward information. These must interact in order for the relationships between cues, actions, and outcomes to be learned. We found that responses of single neurons in midline thalamus to sensory cues are increased when associated with reward. This output may amplify similar signals generated in parallel by the dopamine system. In addition, some neurons coded a three-factor decision in which the neuron fired only if there was a movement, if it was the first one after the reward becoming available, and if it was part of a sequence triggered in response to a preceding cue. These data highlight midline thalamus as an important node integrating multiple types of information for linking sensation, actions, and rewards.

\section{Introduction}

Learning about environmental cues that predict future rewards is critical to optimizing behavior. A growing body of evidence suggests that thalamic midline nuclei may form an important integrative function for reward-mediated behavior (Kelley et al., 2005; Haight and Flagel, 2014) in addition to long-standing research indicating their engagement in processing stress and fear (Hsu et al., 2014). The midline thalamus consists of dorsal, ven-

\footnotetext{
Received March 22, 2015; revised Feb. 14, 2016; accepted Feb. 17, 2016.

Author contributions: B.I.H. designed research; Y.L. and M.J.G. performed research; Y.L., C.L., and B.I.H. analyzed data; C.L. and B.I.H. wrote the paper.

This work was supported by a grant from the Royal Society of New Zealand Marsden Fund. C.L. was supported by a grant from the Neurological Foundation of New Zealand.

The authors declare no competing financial interests.

Correspondence should be addressed to Brian Hyland, Department of Physiology, University of Otago, P.O. Box 913, Dunedin 9054, New Zealand. E-mail: brian.hyland@otago.ac.nz.

DOI:10.1523/JNEUROSCI.1107-15.2016

Copyright $\odot 2016$ the authors $\quad 0270-6474 / 16 / 363567-12 \$ 15.00 / 0$
}

tral, and posterior groups of nuclei. Most is known about the dorsal group: the paraventricular (PVT), intermediodorsal, and parataenial nuclei (Van der Werf et al., 2002).

A role in reward processing is supported by known inputoutput connectivity with reward circuits. Dorsal group nuclei receive prominent monoaminergic inputs and extensive projections from the hypothalamus and brainstem that carry information about internal states (Groenewegen and Berendse, 1994; Krout and Loewy, 2000a, 2000b; Krout et al., 2002). These include fibers from neurochemically specific hypothalamic subpopulations involved in regulation of appetite, some of which contact PVT neurons that in turn project to the nucleus accumbens (NAcc) (Parsons et al., 2006). On the output side, dorsal nuclei are characterized by prominent projections to the striatum, in particular, the NAcc (Van der Werf et al., 2002). The NAcc is a central node for reward processing and a major recipient of inputs from the midbrain dopamine (DA) neurons, which signal salient reward-predicting cues (Schultz, 1998, 2002; Pan et 
A
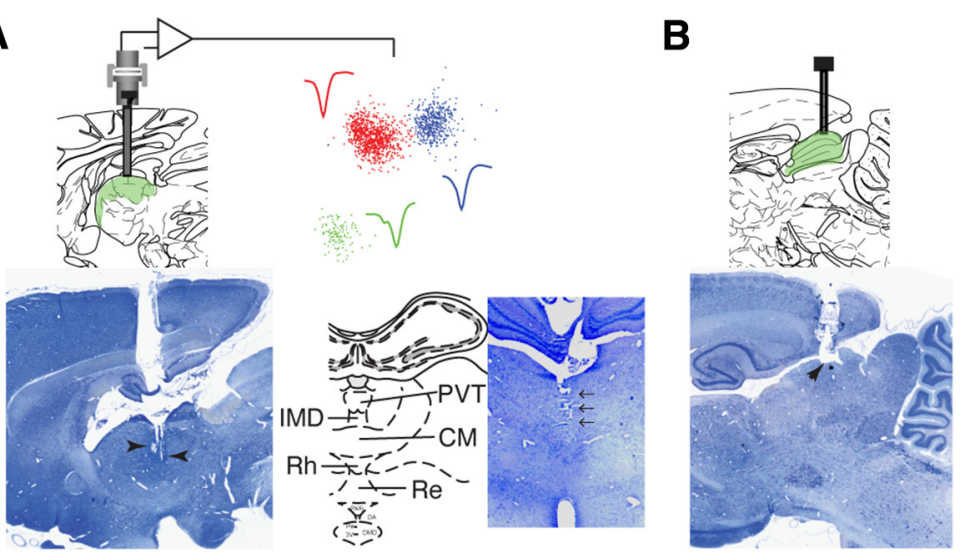

C
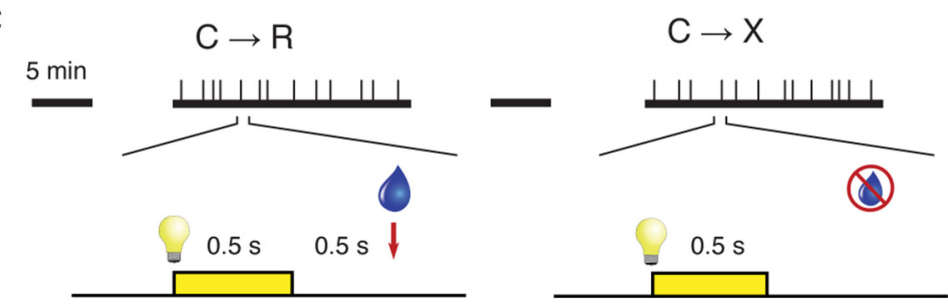

D
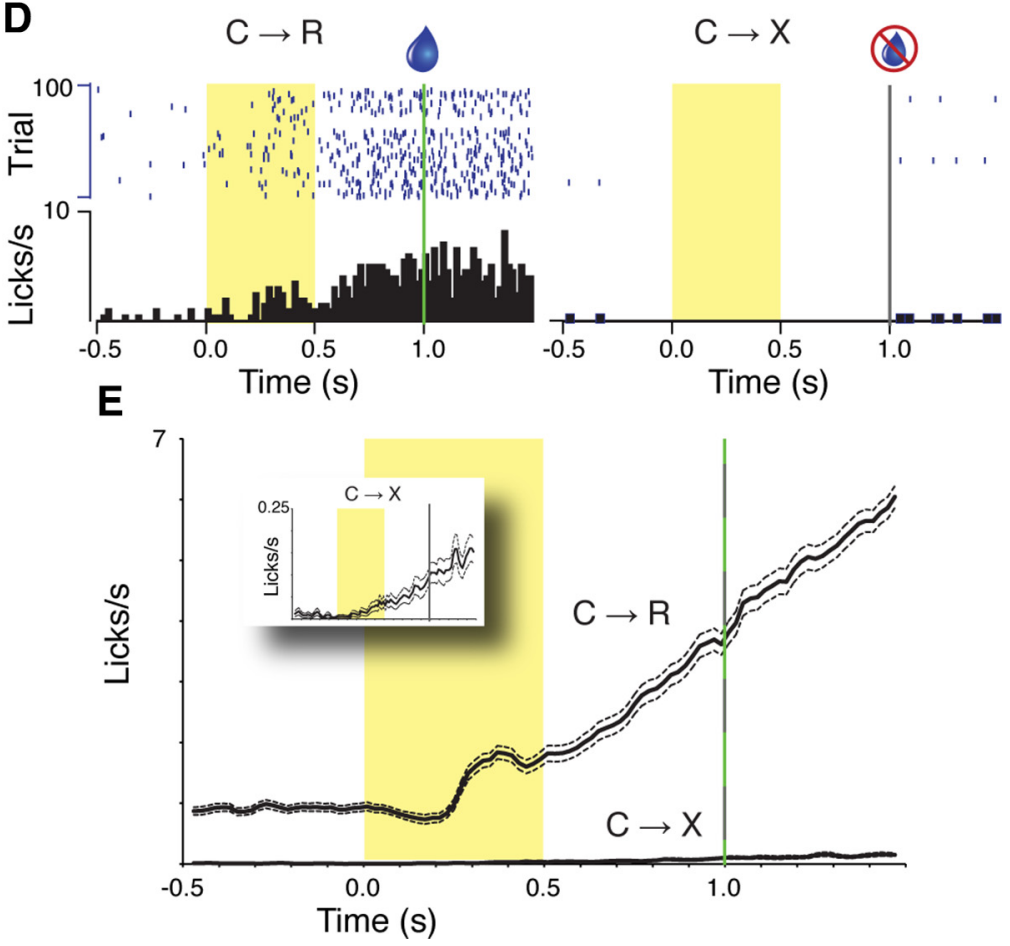

Figure 1. A, Example sagittal histological section (left) shows guide cannula track and electrode tip positions (arrowheads) in midline thalamus. The position of the paraventricular nucleus is indicated on the corresponding atlas section (Paxinos and Watson, 2007), with a superimposed schematic of recording electrode bundle and connection to head-stage amplifier. Scatter plot shows first two principal components for spikes recorded from one electrode separated into three clusters representing different neurons. Waveforms show average calculated from each spike in the respective clusters. The coronal histological section from another rat and corresponding atlas diagram (right) show the recording track in the midline (arrows) and the recording targets, respectively. IMD, Interomediodorsal nucleus; CM central medial nucleus; Rh rhomboid nucleus; RE reunions nucleus. $\boldsymbol{B}$, Sagittal section (from same animal as in $\boldsymbol{A}$, left) and corresponding atlas diagram showing the typical position of injection cannula tracks targeting superior colliculus. C, Schematic diagram summarizing the associative conditioned approach task with repeated acquisitionextinction. Vertical tick marks on thick horizontal lines represent light-cue stimuli at pseudorandom intervals within blocks in which the light cue $(C)$ was either followed by solenoid activation for reward $(R)$ delivery $(C \rightarrow R)$ or not followed by reward $(C \rightarrow X)$. Successive blocks were separated by 5 min rest periods with no stimuli presented. One trial in each block is shown in detail below; yellow bar and light symbol indicates light cue; water droplet symbol indicates solenoid activation for reward delivery. D, Example behavioral (licking) data from one experiment. Rasters show individual licks at fluid spout on each trial; histograms show mean lick rate over whole block. Cue period is indicated by yellow shading; green vertical line marks reward delivery time in $C \rightarrow R$ trials and al., 2005). In the NAcc, a proportion of midline thalamus terminals converge on the same postsynaptic targets as DA fibers and others synapse onto DA terminals, allowing direct modulation of DA release by thalamic neural activity (Jones et al., 1989; Pinto et al., 2003).

Functional evidence for PVT engagement in reward processing comes from experiments showing increased immediate early gene expression in response to environments paired with drug rewards (Brown et al., 1992) and after early conditioning of associations between discrete cues and appetitive reward delivery (Igelstrom et al., 2010); however, whether neurons show time-locked neural spiking activity in responses to individual cues and rewards remains unknown. To investigate this, we made single-neuron recordings from the midline thalamus in freely moving rats using the same Pavlovian procedure with which we previously characterized midbrain DA neuron responses (Pan et al., 2005). Responses to visual cues in DA neurons require inputs from superior colliculus (SC) (Comoli et al., 2003; Dommett et al., 2005) and some data suggest the possibility of projections from SC to midline thalamus (Krout et al., 2001). We therefore made recordings in SC for comparison and tested some midline thalamus neurons after SC inactivation to determine whether responses were SC dependent.

Below the dorsal group lies the caudal part of the central medial nucleus and the rhomboid nucleus (Fig. 1A). These ventral midline nuclei are characterized by projections to motor, sensory, and associative cortical regions, with weak projection to the NAcc (Van der Werf et al., 2002), but little is known about the functional correlates of neuronal activity in them. Given that both dorsal and ventral groups have projections to regions involved in motor control (dorsal striatum and sensorimotor cortex, respectively), we also analyzed the data to detect any licking-movement-related activity. This revealed an unexpectedly rich range of lick-related responses that extended from simple correlations to each lick movement, to highly selective responses, to only the first lick after reward delivery, de-

$\longleftarrow$

the gray vertical line indicates the equivalent time on nonrewarded $C \rightarrow$ X trials, but no signal occurred then. $\boldsymbol{E}$, Main graph shows grand average ( \pm SEM) lick rate from all recording sessions across all rats; inset graph shows $C \rightarrow X$ trials from the main graph with a rescaled $y$-axis. 
pending on the presence or absence of conditioned licking responses to the preceding cue.

\section{Materials and Methods}

Animals and surgery. The University of Otago Animal Ethics Committee approved this study. The neurophysiological, intracerebral infusion methods, and animal handling, including fluid restriction, were as previously described in previous studies of reward circuit neurons (Pan and Hyland, 2005; Li et al., 2013). Adult male outbred Wistar rats were acclimated to handling before surgery for implanting chronic recording and infusion devices. Surgery was performed using sterile technique under general anesthesia ( $75 \mathrm{mg} / \mathrm{kg}$ ketamine plus $0.5 \mathrm{mg} / \mathrm{kg}$ Domitor), with additional local anesthetic along the scalp incision line (Lopaine $0.5 \mathrm{ml}$, $20 \mathrm{mg} / \mathrm{ml}$ ) and systemic antibiotic cover (Strepcin $0.1 \mathrm{ml}$, Procaine Penicillin G 10,000 IU, dihydrostreptomycin $250 \mathrm{mg} / \mathrm{ml})$. Antisedan $(2.5$ $\mathrm{mg} / \mathrm{kg}$, s.c.) was given at the end of surgery to terminate anesthesia and analgesic (Carprofen, $0.1 \mathrm{ml} / \mathrm{kg}$, s.c.) was given for postoperative pain relief.

To gain access to the midline thalamus, we first lowered a 23 gauge stainless steel guide cannula through the dura and sagittal vein into the third ventricle (target stereotaxic coordinates AP $-2.5 \mathrm{~mm}$ relative to bregma, in the midline) and fixed it in place with dental acrylic. This position targeted the middle region of PVT as well the ventral midline nuclei in a single track (Fig. 1A; Van der Werf et al., 2002; Paxinos and Watson, 2007). Bleeding from the vein was usually self-limiting or arrested by applying gentle pressure with sterile gauze. An inner cannula mounted on an on-head microdrive contained the recording electrodes (8 0.001-inch-diameter Formvar-insulated nichrome microwire; A-M Systems) and was lowered through the guide cannula to reach the third ventricle at the dorsal margin of the PVT. The same procedures were used for SC recordings, with the electrodes targeted to AP -6.3 , lateral 1.5 $\mathrm{mm}$, initial depth $3 \mathrm{~mm}$. For SC inactivation experiments, we targeted an injection cannula bilaterally to the dorsal layers of the SC at AP $-6.5 \mathrm{~mm}$, lateral $1.5 \mathrm{~mm}$, and depth $3.5 \mathrm{~mm}$ (Fig. $1 B$ ) in 2 rats.

Behavioral procedures. Animals were maintained on a fluid restriction regimen to motivate them for the task by limiting access to water to that obtained during recording sessions plus $10 \mathrm{~min} / \mathrm{d}$ ad libitum access, with free access for $24 \mathrm{~h}$ on $2 \mathrm{~d}$ of 7 . Animals were monitored with weekly weighing to ensure that they tracked within $\pm 10 \%$ of the expected weight curve for their age and start weight.

Experiments were performed in a dimly lit room. For 1 week before surgery and every subsequent recording day, rats were trained in a repeated Pavlovian associative learning acquisition-extinction procedure that we previously used for recordings from midbrain DA neurons (Pan et al., 2005; Fig. 1C). In this procedure, animals were exposed to sequential blocks of 100 trials. In one block, an arbitrary sensory cue (house light illumination) was followed by activation of a solenoid to deliver saccharin-sweetened water reward $(\mathrm{C} \rightarrow \mathrm{R}$ trials). The cue was $0.5 \mathrm{~s}$ duration and the solenoid was activated $0.5 \mathrm{~s}$ after cue offset. The solenoid generated a low-pitched clicking sound. In the other block, the same light cue was delivered, but the solenoid was not activated $(\mathrm{C} \rightarrow \mathrm{X}$ trials $)$ and no other cues were presented. There was a 5 min rest period between blocks during which no cues were presented, which was much longer than the maximum intertrial interval within blocks ( $20 \mathrm{~s}$ ), and this pause was the only indication that that the contingency had changed. In some sessions, we recorded another $\mathrm{C} \rightarrow \mathrm{R}$ block to confirm continued motivation of the animal to perform the task. Licking at the fluid spout was detected by interruption of an infrared beam crossing the spout opening. Task control signals and beam-interrupt detections were handled by Med-Associates hardware. As illustrated by the example licking data in Figure $1 D$ and the average data in Figure $1 E$, trained animals adjusted their behavior across blocks, exhibiting conditioned licking in response to the cue in reward blocks and minimal licking activity in nonreward blocks.

Single-unit recording procedures and analysis. After $5 \mathrm{~d}$ of postoperative recovery, animals were brought to the recording room daily and the electrodes were advanced in steps of $\approx 80 \mu \mathrm{m} / \mathrm{d}$ until discriminable neurons encountered and were advanced again once all experiments were completed for each recorded neuron. During recordings, signals were filtered (500 Hz-10 kHz band-pass) and digitized at $32 \mathrm{kHz}$ using a Neuralynx data acquisition system. Spikes were initially discriminated using clustering of waveform parameters in Neuralynx Spikesort3D. Final spike sorting analysis was performed offline using Spike2 software (CED). To test the effect of SC inactivation on responses, after completion of baseline recordings, we made bilateral infusions of the selective $\mathrm{GABA}_{\mathrm{A}}$ agonist muscimol (Sigma-Aldrich; $1 \mathrm{~mm}, 2 \mu \mathrm{l}$ each side, at 1 $\mu \mathrm{l} / \mathrm{min}$ ) or vehicle using a syringe pump and a further set or sets of task blocks recorded beginning $5 \mathrm{~min}$ after completion of the infusion. We used this volume because of the large size of SC and did not know a priori from which region of SC any particular recorded cell might receive input.

To analyze neural responses to task events, we constructed average perievent time histograms (PETHs) using Spike2 software (CED). Excitatory responses were defined as peaks consisting of at least two contiguous 20-ms-wide bins in the PETH that were $>2$ SDs above the mean of the $500 \mathrm{~ms}$ before cue onset. Peak onset latency was measured as the left edge of the first bin in the peak and peak end was marked at the right edge of the last bin before two consecutive bins that fell below the threshold. Statistical analyses of derived measures were performed using Prism 6 (GraphPad Software). Group data in the text are presented as mean \pm $\mathrm{SD}$; graphs show mean \pm SEM.

\section{Results}

We analyzed responses of 477 well discriminated neurons recorded from 176 recording sessions (average 2.7 neurons per session) in 5 rats. Of these, 234 (49\%) showed a phasic excitatory response to the light cue onset in one or both blocks, as illustrated by the examples shown in Figure 2, $A-C$. There was no difference between rats in the proportion of neurons showing an excitatory response $\left(39-63 \%, \chi^{2}(4)=8.46, p=0.076\right)$. In addition to excitatory peaks, postcue troughs in firing rate suggestive of inhibitory responses such as in $\mathrm{C} \rightarrow \mathrm{X}$ trials in the example in Figure $2 A$ were also observed, but were not quantified because of the floor effect when the firing rate drops to zero.

Before quantitative analysis of peak amplitudes, we checked whether the intertrial baseline firing rate (calculated from the 500 ms before cue onset) was consistent between blocks. This revealed a significant effect of block, with baseline rate higher in $\mathrm{C} \rightarrow \mathrm{R}(7.6 \pm 8.3$ spikes/s) than in $\mathrm{C} \rightarrow \mathrm{X}(5.7 \pm 6.2$ spikes $/ \mathrm{s}$; $t_{(233)}=7.698, p<0.0001$, paired $t$ test, $\left.n=234\right)$ trials. Because of this difference, we used baseline-subtracted data in all subsequent analyses.

The majority of visual cue-responsive neurons (164/234, $70 \%$ ) had an excitatory response in only one block, illustrated by the example in Figure $2 A$. In this case, the excitation was only seen in $\mathrm{C} \rightarrow \mathrm{R}$. Although different neurons were selective in this way for $\mathrm{C} \rightarrow \mathrm{R}$ (Fig. $2 A$ ) or $\mathrm{C} \rightarrow \mathrm{X}$ (Fig. $2 B$ ), overall, there was a bias among these selective neurons toward $\mathrm{C} \rightarrow \mathrm{R}$, with the majority $(100 / 164,61 \%)$ responding only in that block, whereas $64 / 164$ $(39 \%)$ were selective for $C \rightarrow X$. This distribution was significantly different from that expected by chance $(p=0.0061$; two-tailed parts-of-whole binomial test with expected values set to $50 \%$ in each group).

In the remaining $30 \%$ of responsive neurons (70/234), excitatory peaks were detected in both blocks, such as the example shown in Figure 2C. However, as in this example, in these cells, the response often appeared greater in $\mathrm{C} \rightarrow \mathrm{R}$ than $\mathrm{C} \rightarrow \mathrm{X}$. To quantify this, we defined cells in which the amplitude of the modulation in $\mathrm{C} \rightarrow \mathrm{R}$ was within $\pm 20 \%$ of that in $\mathrm{C} \rightarrow \mathrm{X}$ as having no difference and those with responses $>20 \%$ bigger or smaller as having larger or smaller response in $\mathrm{C} \rightarrow \mathrm{R}$ than in $\mathrm{C} \rightarrow \mathrm{X}$, respectively. This confirmed a significant bias toward $\mathrm{C} \rightarrow \mathrm{R}$, with 31 of the 70 cells (44\%) having larger responses in $C \rightarrow R$ than $C \rightarrow X, 25$ $(36 \%)$ having equivalent amplitude responses, and only 14 $(20 \%)$ having smaller peaks in $\mathrm{C} \rightarrow \mathrm{R}\left(\chi^{2}(2)=6.4, p=0.04\right.$, 
parts-of-whole $\chi^{2}$ test with expected values set to $33.33 \%$ in each group).

Changes in firing rate were also observed after solenoid activation in $\mathrm{C} \rightarrow \mathrm{R}$ blocks. Because rats accelerated their licking at this time, we checked whether postsolenoid activations were more related to the solenoid or to licking activity by ordering rasters by the time from solenoid activation to the first postsolenoid lick and generating histograms centered on solenoid or first lick time. As illustrated by the example in Figure 2D, this analysis revealed a small proportion (97/477) of neurons assessed as showing responses better associated with solenoid activation. This neuron was typical of the slight majority of solenoid responsive neurons that showed no response to the visual cue (60/ $97,62 \%)$, but the remainder had responses to both. Most of the solenoid responses (84/97) occurred at long latency (160 $\pm 128 \mathrm{~ms}, 20 \mathrm{~ms}$ bin width), leaving their behavioral correlates uncertain. The remainder displayed short-latency, phasic peaks consistent with an auditory response to the click generated by the solenoid ( $n=13$, mean latency $30 \pm 22 \mathrm{~ms}$ with $1 \mathrm{~ms}$ bin width).

\section{Contrasting effects of block on firing} rate over three different time frames

To assess differences between responses to the visual cue in $\mathrm{C} \rightarrow \mathrm{R}$ and $\mathrm{C} \rightarrow \mathrm{X}$ blocks quantitatively at the population level, we analyzed data from all neurons with a response in any block. Figure $3 A$ shows the baseline-subtracted population average (grand mean) PETH. Two features are apparent: (1) the phasic peak response appears larger in amplitude in $\mathrm{C} \rightarrow \mathrm{R}$ than $\mathrm{C} \rightarrow \mathrm{X}$ and (2) there is a sustained, tonic elevation in firing rate during and after the cue in $\mathrm{C} \rightarrow \mathrm{X}$, but not in $\mathrm{C} \rightarrow \mathrm{R}$. To test the significance of these changes, we quantified separate peak and tonic epochs (middle and right inset histograms in Fig. 3A). For analysis of peak amplitudes, we used the mean firing rate between the peak onset and offset times. In neurons in which the peak detection algorithm identified a response in only one block, we applied the onset and offset times of the detected peak to define the epoch for the other block to avoid missing modulations that were below the detection threshold. This analysis (middle inset histogram in Fig. 3A) confirmed that, on average, baselinesubtracted peak amplitudes in $\mathrm{C} \rightarrow \mathrm{R}$ were significantly larger than in $\mathrm{C} \rightarrow \mathrm{X}(4.5 \pm$ 5.5 and $2.95 \pm 3.5$ spikes/s, respectively; $t_{(233)}=4.687, p<0.0001$, paired $t$ test, $n=234)$.
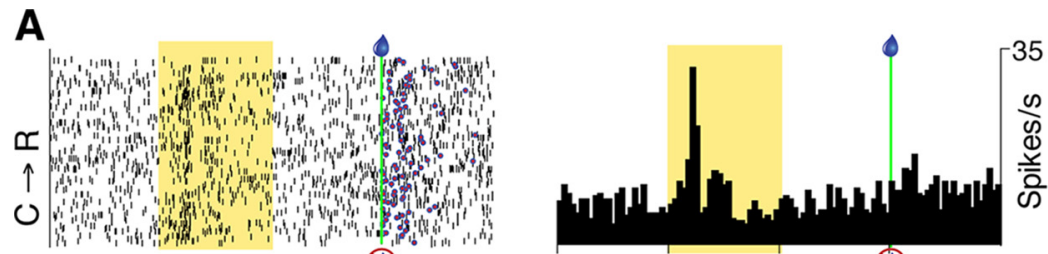

(2)
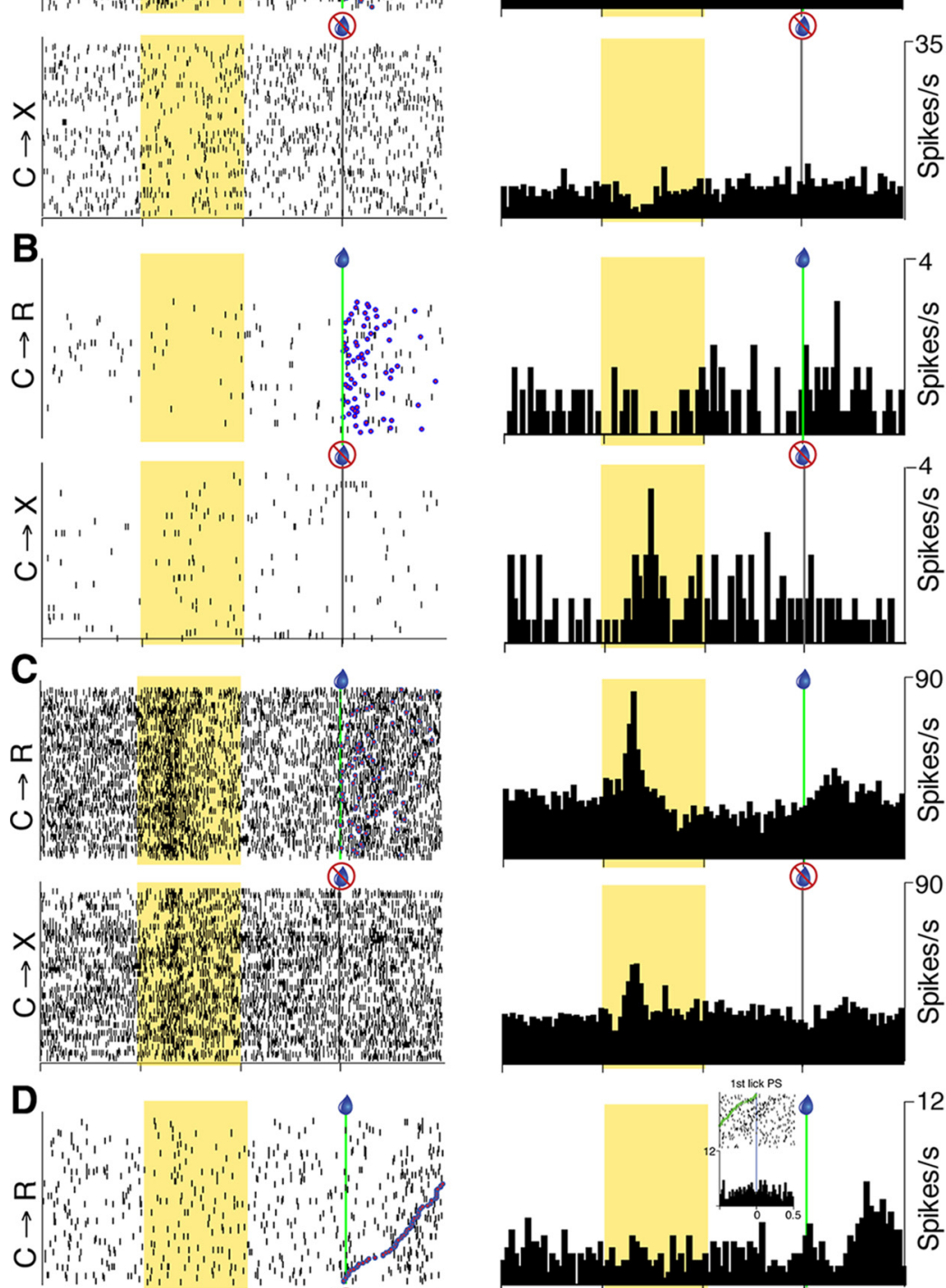

(c)

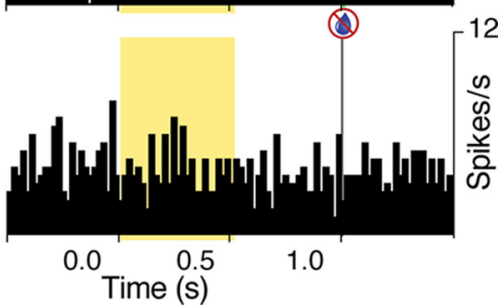

Figure 2. Single-neuron examples of responses to task events. $\boldsymbol{A}$, Example neuron with phasic excitation to visual cue onset only in $C \rightarrow R$. Raster displays (left) show individual action potentials on each trial in reward $(C \rightarrow R)$ and nonreward blocks $(C \rightarrow X)$. Trials are aligned to cue onset. Vertical green line and blue droplet symbol indicate solenoid activation in $C \rightarrow R$ trials; gray vertical line marks the same time on $C \rightarrow$ X trials (no solenoid activation). Trials are in original time order. Blue circles with red fill on $C \rightarrow R$ raster indicate time of first lick after solenoid activation. PETHs (right) show the data averaged across each block (20 ms bins). $\boldsymbol{B}$, Neuron with a phasic response only in $C \rightarrow$ X. C, Neuron with phasic responses in both blocks. $\boldsymbol{D}$, Neuron with no response to the light cue in either block, but a late, broad excitation after solenoid activation. Raster trials in $C \rightarrow$ Rare ordered according to the time from solenoid activation to the first postsolenoid lick. Inset raster and histogram show data from same block, but aligned to time of the first postsolenoid (PS) lick (vertical line at time $=0$ ), with the time of solenoid activation on each trial marked by green circles on the raster. 


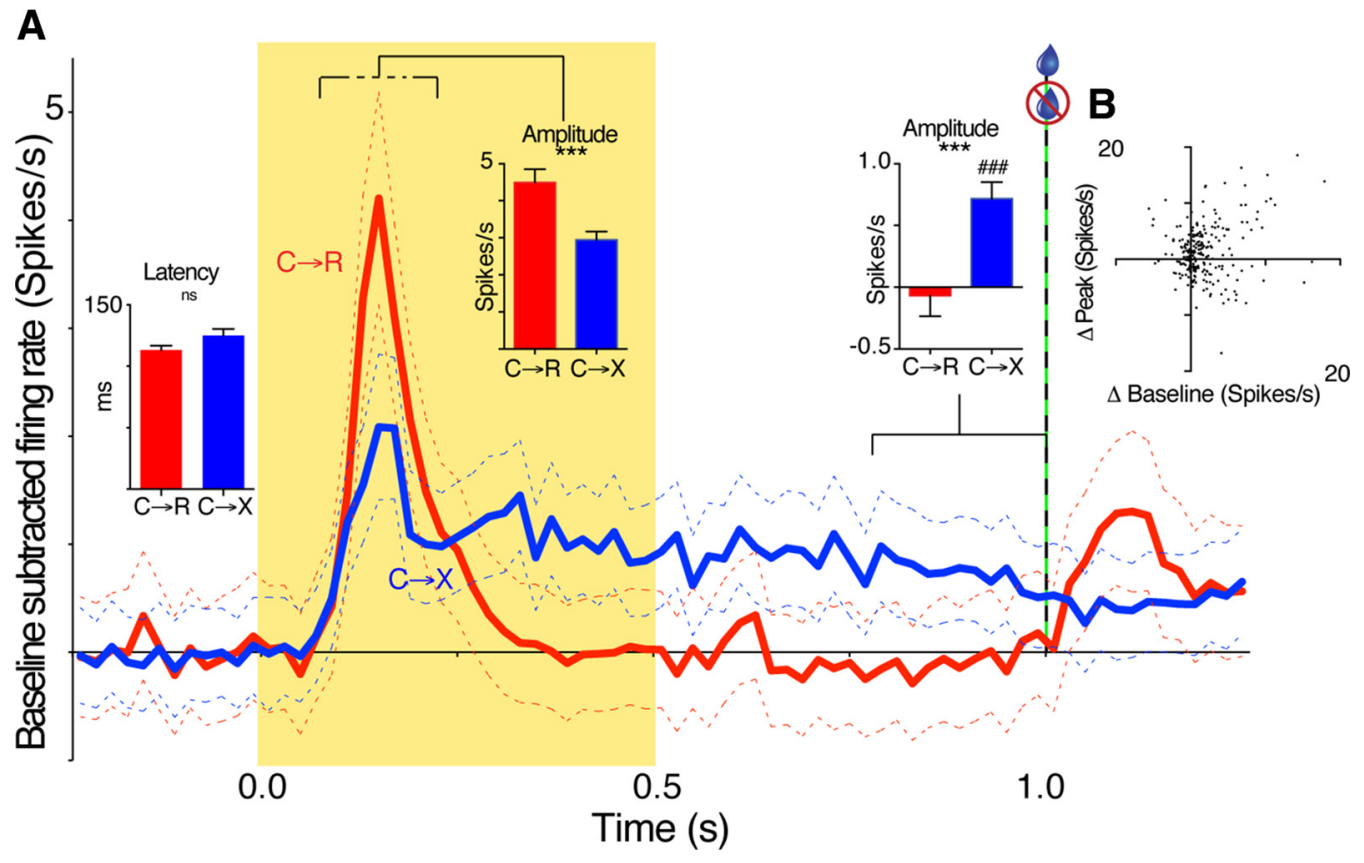

Figure 3. Population analysis of neural responses to task events. $A$, Main graph traces show grand mean ( \pm SEM) baseline-subtracted PETH from all neurons with an excitatory response in at least one block for $C \rightarrow R($ red) and $C \rightarrow X$ (blue) blocks. Inset bar graphs show mean \pm SEM of, from left to right, the latency of all phasic peaks that ended within 275 ms of cue onset, the average baseline-subtracted amplitude of phasic peaks, and the mean baseline-subtracted firing rate over last $250 \mathrm{~ms}$ of the presolenoid period. Dashed line above the peak period indicates that the measured period was variable, being set for each individual according to peak onset and offset times. ns, Not significant; ${ }^{* *} p<0.001$, paired $t$ test, $n=234$; \#\#\#p $<0.001,1$-sample $t$ test, compared with $0 ; n=234$. B, Scatter plot shows the relationship for each cell of the difference in baseline-subtracted firing rate of excitatory peaks between $C \rightarrow R$ and $C \rightarrow X$ blocks $(\Delta$ peak), and the difference in baseline firing rate between the blocks ( $\Delta$ baseline). One outlier data point (respective values $31,27 \mathrm{spikes} / \mathrm{s}$ ) is omitted from the graph but was included in the statistical analysis. There was no significant correlation.

The time course of the initial slope of the phasic peaks in the respective smoothed population $\mathrm{PETH}$ in Figure $3 A$ completely overlapped, suggesting similar latency of this initial component. To quantify this, we analyzed the onset time for individual neuron PETH peaks using unsmoothed data. We restricted analysis to those that had peak offset time of 275 ms or less after cue onset; that is, those that fell within the envelope of the initial peak in the population average. This confirmed no significant difference between onset latencies for these early phasic peaks between the two blocks (left inset histogram in Fig. $3 A ; \mathrm{C} \rightarrow \mathrm{R} 113 \pm 41 \mathrm{~ms}, n=$ $124 ; \mathrm{C} \rightarrow \mathrm{X} 125 \pm 49 \mathrm{~ms}, n=82, t_{(204)}=1.87, p=0.064$ unpaired two-tailed $t$ test).

To quantify tonic responses, we measured the baselinesubtracted firing rate in the $250 \mathrm{~ms}$ immediately preceding the time of solenoid activation in $\mathrm{C} \rightarrow \mathrm{R}$; that is, beginning $250 \mathrm{~ms}$ after the light cue offset (right inset histogram in Fig. $3 A$ ). This confirmed that the tonic firing rate over the last $250 \mathrm{~ms}$ of the pre-solenoid period was higher in $\mathrm{C} \rightarrow \mathrm{X}(0.72 \pm 2.1 \mathrm{spikes} / \mathrm{s})$ than in $\mathrm{C} \rightarrow \mathrm{R}\left(-0.07 \pm 2.5\right.$ spikes $/ \mathrm{s} ; t_{(233)}=3.769, p=0.0002$, paired $t$ test). Further, the firing rate at this time was significantly different from baseline in $\mathrm{C} \rightarrow \mathrm{X}\left(t_{(233)}=5.315, p<0.0001\right.$, 1 -sample $t$ test $)$, but not in $\mathrm{C} \rightarrow \mathrm{R}\left(t_{(233)}=0.4140, p=0.7\right)$. Therefore, the effect of block on tonic responses during and after cue presentation was in the opposite direction to that for the early phasic cue response and for intertrial baseline firing rate, suggesting that the tonic response to the cue in $\mathrm{C} \rightarrow \mathrm{X}$ blocks was due to recruitment of a specific, different pattern of inputs compared with the intertrial or peak response periods.

Both precue baseline rate and early phasic cue-response amplitude were increased in $\mathrm{C} \rightarrow \mathrm{R}$ compared with $\mathrm{C} \rightarrow \mathrm{X}$. To determine the extent to which these two effects, both involving increase in rate, could reflect a common underlying mechanism (e.g., a sustained increase in excitatory drive), we calculated the correlation between the difference in baseline firing rate and the difference in baseline-subtracted peak amplitude for each neuron. However, there was no significant correlation (Fig. 3B; Spearman $r=0.107, p=0.10, n=234$ ), suggesting contributions from distinct processes to the increases in relative firing rate at these times.

\section{Rapid switching of neural activity between blocks}

Before the first trial of a new block, the only indication to the animals that the contingency had changed was the 5 min rest period during which no cues were delivered. To determine the extent to which this pause might have provided a learned contextual signal, we examined the rapidity with which licking behavior adapted from one block to the next. Figure $4 A$ shows grand mean lick rates for the first and second trials of each block calculated from all recording sessions (including those in which no responsive cells were found). After the pause after $\mathrm{C} \rightarrow \mathrm{R}$ blocks, the very first trial of $\mathrm{C} \rightarrow \mathrm{X}$ already exhibited loss of baseline licking activity in the interval before the onset of the first cue (i.e., before the first exposure to the lack of reward) and no conditioned licking after cue onset, although there was a very low rate of exploratory licking that developed around the time that reward had previously been delivered. Conversely, the very first trial of $\mathrm{C} \rightarrow \mathrm{R}$ after the previous $\mathrm{C} \rightarrow \mathrm{X}$ block showed some conditioned licking response in the cue-solenoid interval, which strengthened on the second trial, by which time intertrial licking was also established.

To determine whether measures of neural activity showed similarly rapid changes, we compared baseline firing rates and peak amplitudes from the end of one block with the beginning of the next. Because trial-by-trial variation in single neural activity is more variable than licking behavior, for this analysis, we averaged 
across miniblocks of five trials. For baseline firing, we calculated the mean baseline rate for the last five trials of $\mathrm{C} \rightarrow \mathrm{R}$ block for all neurons with at least 95 available trials and compared this with the values calculated for the first two sequential groups of five trials in the $\mathrm{C} \rightarrow \mathrm{X}$ block. $\mathrm{A}$ repeated-measures ANOVA with Geisser-Greenhouse correction for sphericity revealed a significant decline in baseline firing rate across the trial subsets $\left(F_{(1.43,297.4)}=5.78, p=0.008, n=208\right)$. Post hoc tests revealed a possible trend for the first 5 trials after the changeover to have lower baseline firing rates $(5.7 \pm 6$ spikes/s) than prior $(6.4 \pm 6.3$ spikes/s; 95\% confidence interval of difference -0.19 to 1.65$)$, which reached significance for the second 5 trials $(5.3 \pm 5.5$ spikes/s; 95\% confidence interval $0.37-$

1.88 ; Dunnett's multiple-comparisons test, comparing each postsubset with the presubset).

To assess the rapidity of change in cue response amplitude, we used a qualitative approach based on population average PETH because PETH calculated for each cell from a single trial were too noisy to allow objective peak detection and quantification with the algorithm used for the block overall. Because we were looking to assess the rapidity of change between responsive and nonresponsive neurons, we selected neurons for this analysis that had a response detected in only one block in the overall PETH and performed two separate analyses: one for neurons that had a response in $\mathrm{C} \rightarrow \mathrm{R}$ overall, but lost it in $\mathrm{C} \rightarrow \mathrm{X}$, and another for neurons that had no response in $\mathrm{C} \rightarrow \mathrm{R}$ overall, but gained one in $\mathrm{C} \rightarrow \mathrm{X}$. With this subset of neurons, even for the population average, single-trial data proved difficult to interpret. We therefore compared the grand means from individual neuron PETH that were derived from the last five trials of the first block and for the first five trials of the second block. The results are shown in Figure $4 B$ and, although the traces are still relatively noisy because of the small number of trials, they suggest that, on average, responses were lost or gained within five trials from the beginning of the second block.

\section{SC inactivation disrupts phasic responses to reward-predicting cues}

Responses to reward-predicting cues in midbrain DA neurons are dependent on inputs from SC (Comoli et al., 2003; Dommett et al., 2005). It was therefore of interest to determine whether SC may also be involved in generating responses in midline thalamus. First, we examined responses of 47 SC neurons to the light cue in four rats to confirm that response latencies to signals in our task are consistent with transmission of visual information to midline thalamus. Of these, 24 showed short-latency excitatory phasic responses to light-cue onset, with some individual neurons also having tonic activity during the cue, such as the example in Figure 5. Although the response to cue onset in this neuron appeared to be slightly stronger in $\mathrm{C} \rightarrow \mathrm{R}$ than $\mathrm{C} \rightarrow \mathrm{X}$ (Fig. $3 A$ ), overall, among 8 neurons tested in both blocks, there was no difference in mean modulation amplitude $\left(t_{(7)}=0.9071 p=0.4\right.$, paired $t$ test). Interestingly, in this neuron, the response to the cue included a marked change in oscillatory firing in the gamma range, which also seemed to be more prominent in $\mathrm{C} \rightarrow \mathrm{R}$ (Fig. $5 B)$, consistent with previous observations of modulated gamma-
B
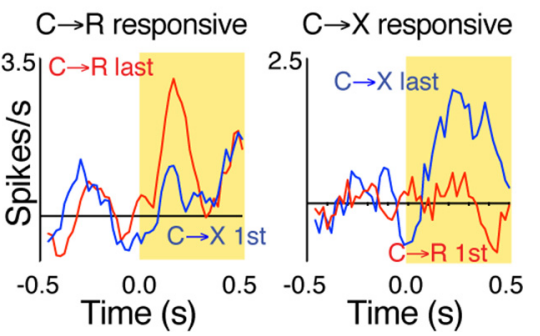

Figure 4. Rapid adaption of behavioral and neural responses between blocks. $A$, Licking behavior. Graph shows grand mean lick rate calculated from only the first and second trials of each block for $C \rightarrow R(R \# 1, R \# 2)$ and $C \rightarrow X(X \# 1, X \# 2)$. Data were smoothed overall PETH calculated from the entire block had an excitation in $C \rightarrow$ R but not $C \rightarrow X$. Right graph shows data from neurons with a response in overall $\mathrm{PETH}$ in $\mathrm{C} \rightarrow \mathrm{X}$ but not $\mathrm{C} \rightarrow \mathrm{R}$.

frequency activity in SC neurons (Lo et al., 1998; Brecht et al., 2001). However, too few such oscillatory neurons were recorded to determine whether this was a consistent effect. Importantly, as illustrated by the overlay of data from a typical midline thalamus neuron on the PETH of the example SC neuron in Figure $5 A$, the average latency of phasic excitatory responses to the light onset in the SC neurons was significantly shorter than for early peaks (those terminating within $275 \mathrm{~ms}$ of cue onset) in midline thalamus neurons in both $\mathrm{C} \rightarrow \mathrm{R}$ (PVT $113 \pm 41 \mathrm{~ms}, n=124$, SC $79 \pm$ $\left.47 \mathrm{~ms}, n=10 ; t_{(132)}=2.5, p=0.014\right)$ and $\mathrm{C} \rightarrow \mathrm{X}$ blocks (PVT $125 \pm 49 \mathrm{~ms}, n=82$, SC $78 \pm 36 \mathrm{~ms}, n=23 ; t_{(103)}=4.2$, $p<0.0001)$.

To determine whether SC activity is necessary for expression of phasic light-cue responses in the midline thalamus, we made bilateral infusions of muscimol into SC of two rats. A total of 13 midline thalamus neurons that showed robust responses to cue onset were selected for testing in six separate muscimol experiments. These recording sessions included an additional eight neurons that had no excitatory cue response. Rats continued to retrieve fluid after muscimol infusion, but there was a small increase in mean latency to the first lick after solenoid activation from $0.61 \pm 0.43 \mathrm{~s}$ before to $1.32 \pm 0.96 \mathrm{~s}$ after the infusion $\left(t_{(5)}=2.863, p=0.035\right.$, paired $t$ test, $\left.n=6\right)$.

SC inactivation reliably reduced the amplitude of the cue responses of the tested midline thalamus neurons, as illustrated by the example neuron shown in Figure $6 A$. The suppressive effect of SC inactivation on response peak amplitudes was confirmed at the population level using the first postmuscimol block across all tested neurons. Because of the time required to achieve both before and after muscimol infusions and the handling involved, not all neurons were held long enough for testing in both $\mathrm{C} \rightarrow \mathrm{R}$ and $\mathrm{C} \rightarrow \mathrm{X}$ blocks, so final numbers with both before- and aftermuscimol data for paired comparisons were $n=10$ for $\mathrm{C} \rightarrow \mathrm{R}$ and $n=8$ for $\mathrm{C} \rightarrow \mathrm{X}$. The effect of muscimol infusion on average modulation amplitude of phasic responses is shown in Figure $6 B$. A two-way repeated-measures ANOVA with factors time (before, after muscimol) and block $(\mathrm{C} \rightarrow \mathrm{R}, \mathrm{C} \rightarrow \mathrm{X})$ confirmed a significant reduction in response amplitude after muscimol infusion across both $\mathrm{C} \rightarrow \mathrm{R}$ and $\mathrm{C} \rightarrow \mathrm{X}$ blocks (significant main effect of time $\left(F_{(1,16)}=14.41, p=0.0016\right.$, and no significant time $\times$ block interaction). There was no effect on baseline firing rates of the neurons in either $\mathrm{C} \rightarrow \mathrm{R}$ (before, $6.2 \pm 6.9$; after, $6.7 \pm 7.6$ spikes $/ \mathrm{s}, t_{(9)}=1.095, p=0.3$ paired $t$ test) or $\mathrm{C} \rightarrow \mathrm{X}$ (before, $4.9 \pm$ 

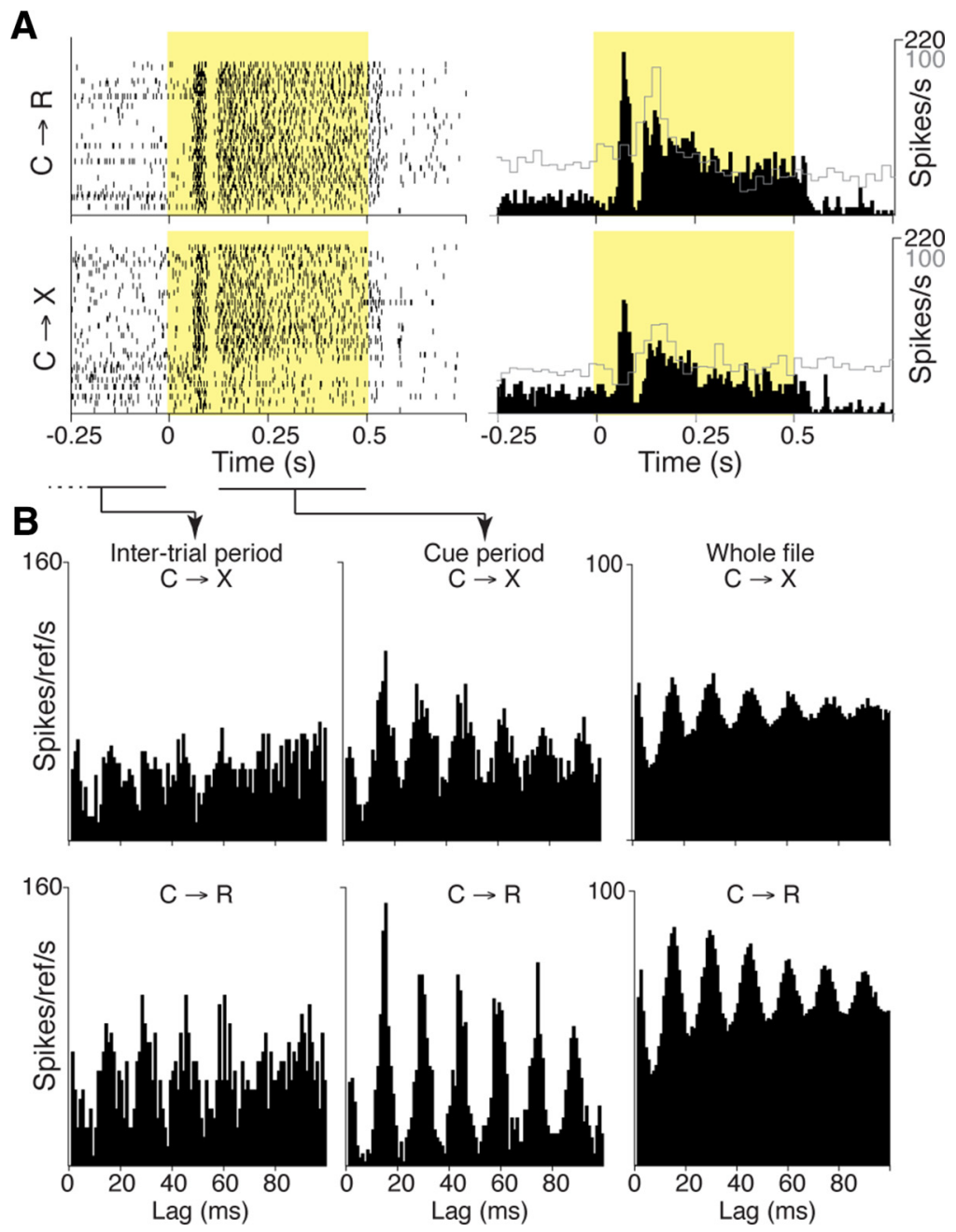

Figure 5. Example of response to sensory cue in an SC neuron. $A$, Dot rasters and solid black histograms show firing rate response of an $\mathrm{SC}$ neuron that had both phasic and tonic responses to light cue in reward ( $C \rightarrow R$, top) and no-reward $(C \rightarrow X$, bottom) blocks. Cue period is marked by yellow shading. Overlaid gray skyline histograms show data from the midline thalamus neuron from Figure $2 C$ at the same time scale, but different vertical scale (100 spikes/s). $\boldsymbol{B}$, Histograms showing autocorrelation analyses for the neuron shown in $\boldsymbol{A}$ from different recording epochs relative to cue onset separately for $C \rightarrow R$ and $C \rightarrow X$ trials. Left, Autocorrelation histogram for reference spikes (time 0 ) occurring during the last $275 \mathrm{~ms}$ of the intertrial interval (the time period indicated by the dashed and solid horizontal line below the dot raster display in $A$ ). Middle, Autocorrelation for spikes occurring during the tonic phase of the cue response (time period indicated by the solid horizontal line below the cue period in the dot rasters in $A$ ). Right, Autocorrelation from all spikes in the file.

6.4; after, $5.4 \pm 5.7, t_{(7)}=0.2951, p=0.8$ ) and none of the simultaneously recorded neurons that lacked an excitatory cue response before muscimol infusion developed a response after infusion. These data therefore suggest a specific effect of SC inactivation on mechanisms that induce enhanced firing in response to cues in midline thalamus, rather than a general effect on cellular excitability.

The effect of muscimol infusion was reversible, as demonstrated by the experiment shown in Figure $6 C$, which shows data for a neuron tested in four successive blocks of 50 trials after muscimol infusion. In this neuron, before muscimol, there was a strong phasic response to cue onset, which faded in the first and second postinfusion block and then began to recover in the third block, albeit with somewhat longer peak latency, and was restored fully by the fourth period. This functional reversibility indicates that the infusion into SC did not produce a permanent lesion. To investigate this further, we examined subsequent recording history for animals that had SC infusion experiments. In all cases, recordings on subsequent days continued to yield neurons with robust response to cues. We quantified this by comparing the modulation amplitudes of cue responsive neurons recorded in the session immediately before muscimol infusion $(n=13)$, with those recorded on the next recording session (9-21 d later; $n=15)$. For $\mathrm{C} \rightarrow \mathrm{R}$ blocks, the mean before was $4.2 \pm 4.4$ spikes/s and, on the next session, $5.2 \pm 3.7$ spikes/s, whereas for $\mathrm{C} \rightarrow \mathrm{X}$, the values were $2.8 \pm 2.8$, and $2.2 \pm 2.6$, respectively. A two-way repeated-measures ANOVA for block $(\mathrm{C} \rightarrow \mathrm{R}, \mathrm{C} \rightarrow \mathrm{X})$ and time (neurons tested before muscimol infusion, neurons tested next session after the muscimol experiment) confirmed a main effect of block just as in the overall data, with responses overall being larger in $\mathrm{C} \rightarrow \mathrm{R}$ than $\mathrm{C} \rightarrow \mathrm{X}$ in this subset $\left(F_{(1,26)}=6.64, p=0.016\right)$, but no significant main effect of time $\left(F_{(1,26)}\right.$ $=0.06, p=0.81)$ and no time $\times$ block interaction $\left(F_{(1,26)}=0.88, p=0.36\right)$. Therefore, neurons recorded after a muscimol infusion experiment were just as responsive as those recorded before, suggesting no permanent loss of SC function from the prior infusion.

\section{Lick-related activity in midline thalamus}

In addition to responses to rewardpredicting sensory cues, we noted a variety of types of lick-related activity. The most straightforward was a one-to-one relation of neural firing rate modulations with each lick event, seen in 37 neurons, such as those illustrated in Figure 7, $A$ and $B$. These modulations in rate occurred either nearly synchronously with the lick detection, as typified by the neuron shown in Figure $7 A$, or slightly before lick detection, as in the inhibitory responses in the neuron in Figure $7 B$. This timing suggests a relationship to motor commands rather than somatosensory or gustatory sensory feedback signals from the licking. Nevertheless, many of these same neurons $(57 \%, 21 / 37)$ also showed a shortlatency phasic response to the onset of the cue (Fig. $7 B$ ), a time when there was no consistent change in licking behavior, and thus consistent with convergence of both sensory and motorrelated inputs to these neurons.

In addition to activity simply related to every lick, we identified another 38 neurons that showed "lick-related activity" that consisted of only a single peak that aligned best with the first postsolenoid lick, with no obvious response to preceding or following licks. As illustrated by the example neuron in Figure $7 C$, our analysis enabled first postsolenoid lick responses to be distinguished from responses to the solenoid, including when they both occurred in the same neuron. Of these first postsolenoid lick responses, eight were relatively broad (Fig. $7 C$ ), but the majority $(n=30)$, were brief, phasic excitations, precisely aligned ( \pm 1 bin, $\approx 20 \mathrm{~ms}$ ) to the time of the lick (Fig. 7D). Similar to the neurons 
with activity aligned to all licks, this group with more selective lick responses divided approximately equally into one subset that also had phasic responses to the visual cue $(18 / 38,47 \%)$ and a separate population with no visual response $(20 / 38,53 \%)$.

Ordering the trials in raster displays aligned to the first postsolenoid lick according to the time delay from the solenoid revealed another, unexpected property in many of these first postsolenoid lick responses. Whereas, in some neurons, the response was relatively consistent from trial to trial (Fig. $7 C, D$ ), in others, such as in the example shown in Figure $7 E$, there was considerable variation in the response, which the ordering revealed to be dependent on the time interval from solenoid activation to the first lick. In the neuron shown in Figure $7 E$, for example, the response was only apparent for trials with short intervals. Further, inspection of these ordered rasters suggested that responses clustered on trials that fell either above or below an inflection in the slope formed by the time of solenoid activation. This is of interest because, as illustrated by the lick data in for the neurons shown in Figure 7, $A, D$, and $E$, the inflection in the distribution of solenoid times across trials in the rasters largely reflects the presence or absence on the trial of conditioned licking behavior that began after cue onset and before solenoid activation. The inflection arises because on trials with licking established before solenoid (LE trials), the maximum solenoid/first lick time is limited to the typical interlick interval $(100-200 \mathrm{~ms})$ generated by the relatively fixed $5-10 \mathrm{~Hz}$ lick rhythm (Corbit and Luschei, 1969). In contrast, on trials without established licking, the first postsolenoid lick represents the beginning of a new sequence of licks made in response to the solenoid and so requires a minimum reaction time of the order of 200 ms, with no specific maximum reaction time. This allows the solenoid to first-lick intervals to spread over a much wider range. Although random licks or initiation of licking sequences could also occur within 0-200 ms of the solenoid by chance, these instances were rare. We therefore used the inflection to parse LE and new sequence (NS) trials for separate PETH analyses to assess the extent to which individual neurons displayed different patterns of responding for the two trial types, as shown in Figure 7, D and $E$.

Figure $7 F$ shows the result of analysis of the relative amplitude of first postsolenoid lick responses in LE and NS trials for all neurons. For this, we first $Z$-score normalized the respective PETH and then computed the binwise difference between them. This revealed a continuum of response variability, from neurons with numerically larger response in LE trials, through neurons with relatively similar response amplitudes, to neurons with larger responses in NS trials. Importantly, the great majority of neurons showed greater amplitude in LE trials; that is, trials in which a licking sequence had been initiated before solenoid activation. Finally, to quantify in an unbiased way the net output of the recorded midline thalamus neurons across the two trial types, we calculated the population average firing rate PETH from all neurons, which is plotted in Figure 7G. This confirmed relatively enhanced response amplitude on LE trials at the population level.
To determine whether there were any trends in the relative incidence of different response types as the electrodes traversed different nuclei within the midline thalamus, we made an approximate assessment of the relative position of neurons with different types of responses (Figure $8 A$ ). It is important to focus on differences between neuron groups at any one depth because the electrode bundles reached different depths across rats, so the overall proportion of neurons at deeper positions would be expected to be lower. Despite this caveat, the analysis provides some support for differential distributions. Neurons with cue responses that were larger in $\mathrm{C} \rightarrow \mathrm{R}$ than $\mathrm{C} \rightarrow \mathrm{X}$ tended to be dorsal, probably within PVT. In contrast, first postsolenoid lick responses appeared to be enriched more ventrally, whereas simple lick-related activity spanned both dorsal and more ventral sites.

\section{Discussion}

We found that midline thalamus neurons exhibit complex activity in relation to multiple task events. First, neurons displayed higher baseline firing rate in rewarded blocks than nonrewarded blocks. Second, there were phasic and tonic responses to sensory cues, with phasic responses larger in reward blocks but tonic components more prominent in nonreward. Third, neurons showed lick-related activity of several levels of complexity, from simple lick-correlated modulations to highly selective responses to only the first lick after reward delivery.

Phasic responses to light cues were larger in amplitude when the cue predicted reward. This is consistent with the previous finding that PVT neurons show enhanced expression of c-fos when cues are paired with reward compared with when the cues and rewards are randomly intermingled (Igelstrom et al., 2010). Changes in cue response, as well as baseline firing rate, occurred within five to 10 trials after transition from one block to another. Together with behavioral data indicating that changes were present on the very first trial, this suggests that, although some relearning was evident, rats were able to anticipate to some extent the changed contingency, perhaps from the pause in cue delivery during the interblock interval. 

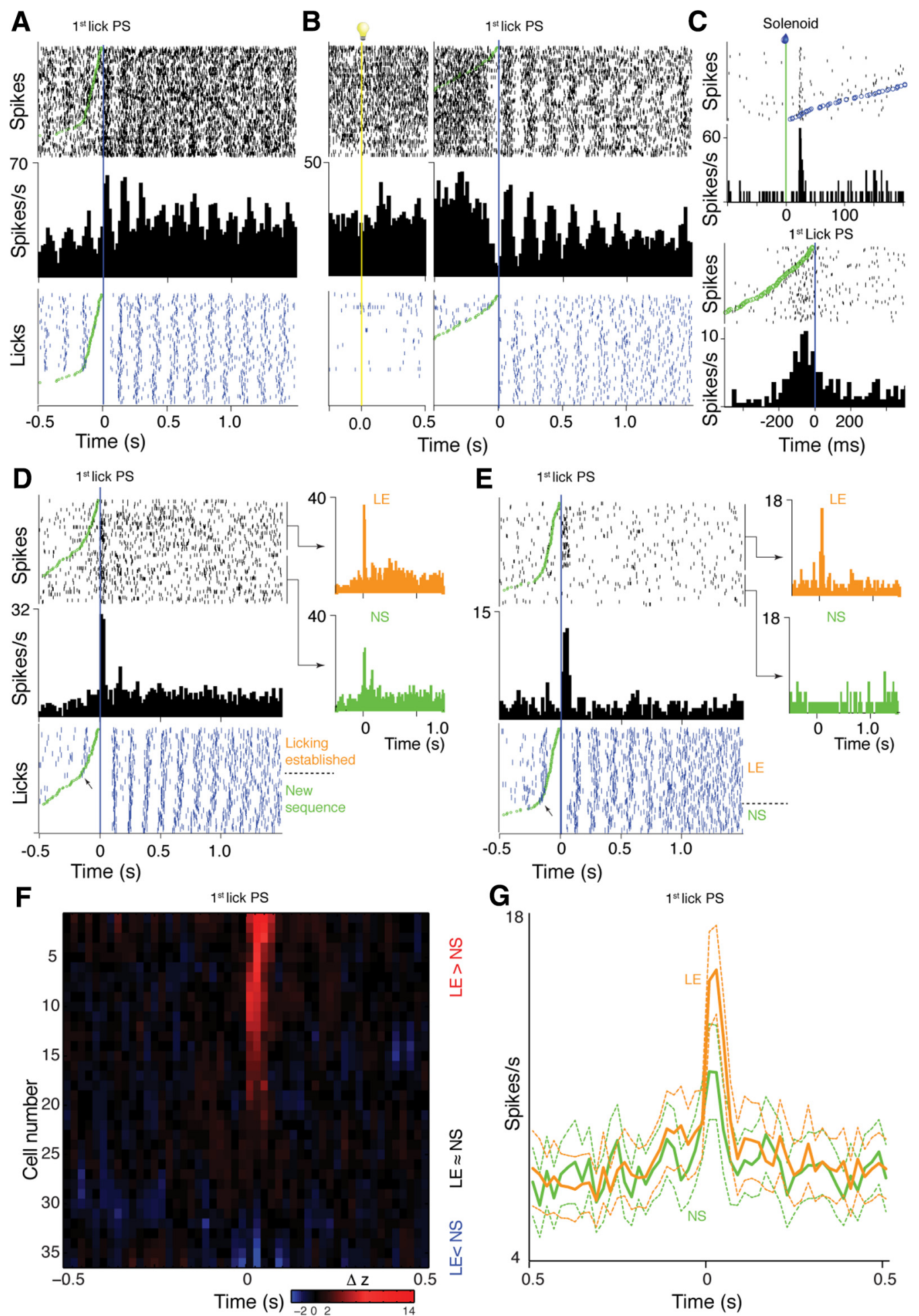

Figure 7. Lick-related activity. A, Simple lick-related excitation. Top raster and the histogram show spike data (20 ms bins), bottom raster shows licks (blue ticks), all aligned to first postsolenoid (PS) lick (blue line). Raster lines ordered by time from solenoid (green circles) to first lick PS. B, Simple lick-related inhibition in a neuron that also had an excitatory response to cue onset. Two PETHs are shown; in the left part, data are aligned to light cue onset (vertical yellow line and light symbol); in the right part, data are aligned to first lick PS. C, Neuron showing distinct solenoid and first-lick PS responses. Top histogram (1 ms bins) and raster aligned to solenoid activation (green line); raster lines are ordered by time from solenoid to the first lick PS (blue circles). Bottom histogram (20 ms bins) shows the same data aligned to the first lick PS (blue vertical line). Green circles mark solenoid activation time. D, Neuron with an excitatory response only to the first lick PS. Arrow on lick raster indicates division between licking established (LE) and new sequence (NS) trials separately averaged in orange and green PETH, respectively. $\boldsymbol{E}$, Neuron with a response to the first lick PS that was limited to LE trials.F, Heat plot raster (centered on first lick PS) shows the binwise difference (smoothed with a 3-bin rolling average) between Z-score-normalized PETHs calculated from LE and NS trials for all neurons with first-lick PS responses, except one neuron with a strong phasic LE $>$ NS response that had no baseline activity for Z-score calculation. Neurons are sorted in order of the difference in Z-score at the typical latency of peaks ( $40 \mathrm{~ms}$ ). Delta Z-scores between -2 and 2 (i.e., LEamplitude $\approx N S$ ) set to black. G, Population PETHs for LE and NS trials (mean \pm SEM) calculated from all neurons with first-lick PS responses. 


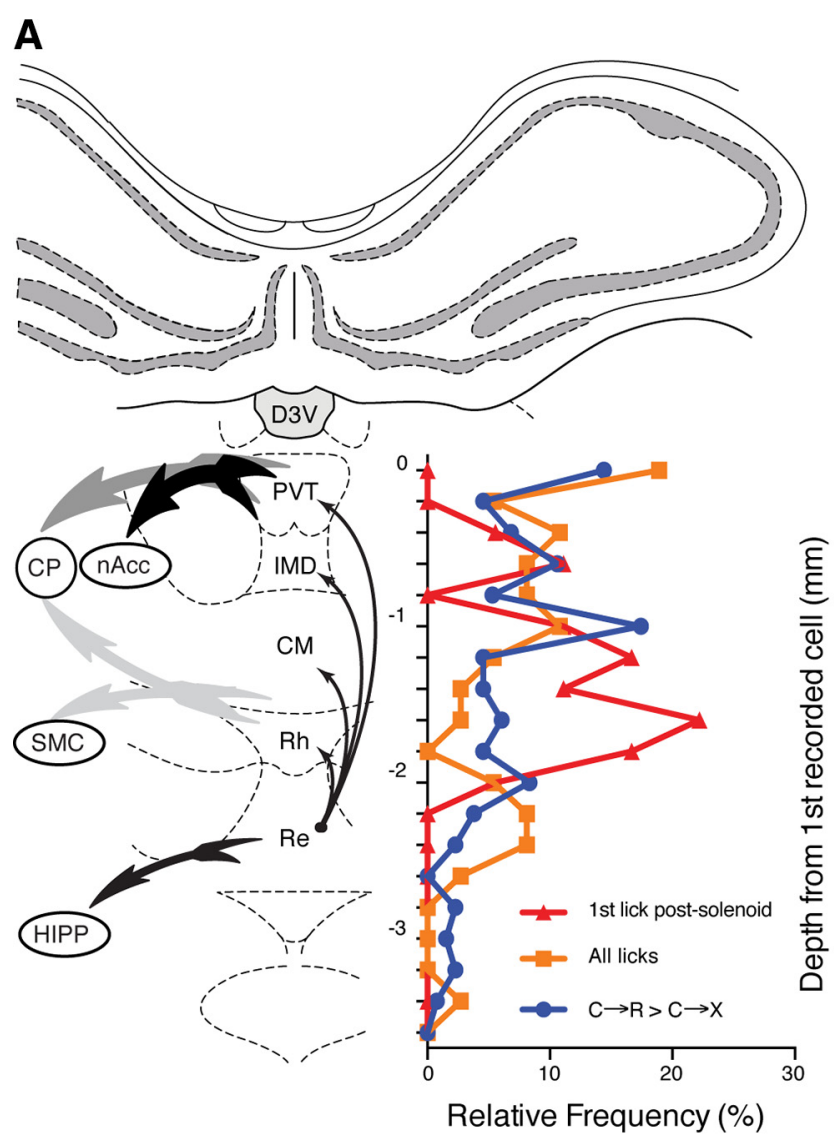

B
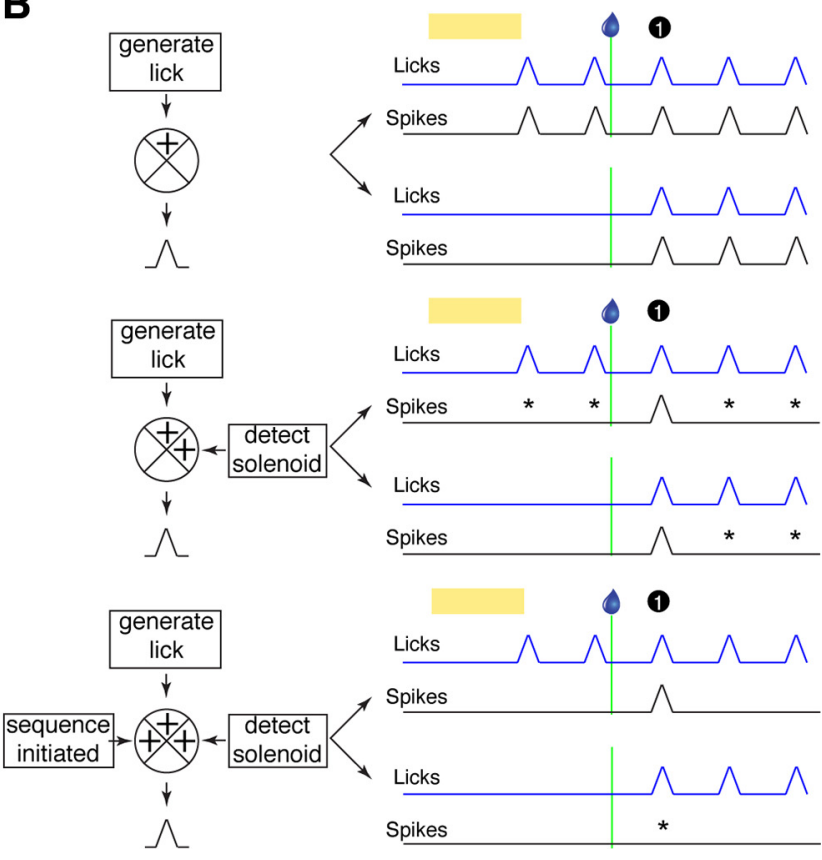

Figure 8. A, Depth profile of recordings. Graph superimposed on coronal section through midline thalamus shows frequency distribution pooled across all electrodes for estimated depths of recorded neurons with different types of activity relative to the first neuron recorded on each electrode, which was assumed to approximate the beginning of the PVT. Blue, Neurons with response to visual cue that was numerically larger in reward $(C \rightarrow R)$ than no-reward $(C \rightarrow X)$ blocks; orange, neurons with simple lick-related activity; red, neurons with lick responses only to the first lick postsolenoid. Thick, tailed arrows indicate projections to key targets from different midline regions, with intensity of shading indicating relative strength of the connections and thin black arrows indicating intramidline connections, all derived from van der Werf et al. (2002). Atlas section is adapted from Paxinos and Watson (2007). CP, Caudate
In contrast to this sensitivity to reward, responses in the nearby lateral intralaminar nucleus in monkeys are influenced by novelty, but not reward (Matsumoto et al., 2001), suggesting that this reward-modulated signaling may be a particular feature of midline nuclei, which have more prominent projections to NAcc. Such signals could reflect incentive motivation (Flagel et al., 2011) or reward-predictive properties of the cues. Another possibility is that the variation in cue response between blocks simply reflects an overall effect of heightened attention during $\mathrm{C} \rightarrow \mathrm{R}$ blocks. Indeed, the increased background firing rate observed in $\mathrm{C} \rightarrow \mathrm{R}$ may reflect enhanced vigilance during the block. However, if a single mechanism such as global heightened attention were responsible for both the baseline and cue response changes, then these effects might be expected to be correlated within neurons, and this was not the case. This suggests that two separate processes contributed to the baseline and peak firing rate changes.

The response latency of phasic cue responses was similar to that reported for midbrain DA neurons to the same visual cue (mean 120 ms; Pan et al., 2005). Afferents from midline thalamus to NAcc converge on the same postsynaptic targets as DA fibers and also modulate DA release directly (Jones et al., 1989; Pinto et al., 2003; Parsons et al., 2007; Ligorio et al., 2009). Given their similar projection distances, cue signals from the midline thalamus would thus be likely to arrive to the NAcc in close temporal proximity to impulses from DA pathways. This anatomical, temporal, and functional convergence is consistent with midline thalamus forming a key node in a parallel pathway by which information from cortical, hypothalamic, and brainstem sources can be integrated to modulate phasic DA signals in NAcc (Jones et al., 1989; Parsons et al., 2006, 2007).

The strong effect of SC inactivation on responsiveness of tested neurons and the shorter latency of SC responses are consistent with a role for SC in triggering cue-evoked excitations in midline thalamus. The SC is known to drive midbrain DA neurons through direct synaptic connections (Comoli et al., 2003; Dommett et al., 2005). It is uncertain whether there are direct projections to midline thalamus. One study using retrograde tracing found evidence of projections from SC toward the entire midline thalamus, but could not rule out involvement of axons of passage (Krout et al., 2001). Another using anterograde tracing found only sparse projections that were restricted to the central medial nucleus (Yamasaki et al., 1986). The latency of midline thalamus responses that we found is similar to that for DA neurons that receive direct inputs (Comoli et al., 2003); nevertheless, the latency differential between SC and midline thalamus could also be consistent with a multisynaptic pathway between them.

Although the inactivation experiments suggest that SC inputs are important to enable midline thalamus phasic cue responses, it

$\leftarrow$

putamen (dorsal striatum); CM, central medial nucleus; D3V, dorsal third ventricle; HIPP, hip pocampus; IMD, interomediodorsal nucleus; Re, reunions nucleus; Rh, rhomboid nucleus; SMC, sensorimotor cortex. $\boldsymbol{B}$, Schematic of how integration across various dimensions could account for patterns of lick-related activity in midline thalamus neurons. Crossed circles on the process diagrams (left) represent neurons in midline thalamus integrating putative inputs (providing information in square boxes) at three successive levels of complexity to generate lick-related activity (black PETH peaks). Right, Respective patterns of lick-related activity. Black and blue lines show stylized PETHs of neural and licking activity, respectively. Yellow bar indicates visual cue and droplet symbol and green line show solenoid activation time. First-lick postsolenoid is indicated by black circle. For each level of integration, the top pair of PETHs represent trials with established conditioned licking in response to cue and the bottom pair show trials where a new sequence of licks was initiated in response to the solenoid. Asterisks on the traces for each level indicate failures to respond to lick events that were responded to on the level above. 
remains unclear whether they are also responsible for determining the differential response amplitudes. Although SC responses can be reward modulated (Ikeda and Hikosaka, 2007) and SC, like PVT, shows elevated c-fos expression selectively for rewardpaired cues during learning of cue-reward associations (Igelstrom et al., 2010), in our small sample, there was no consistent bias toward rewarded cues. Therefore, whereas SC was necessary to trigger responses, differential response amplitudes in midline thalamus may reflect modulatory influences from other inputs (Yamasaki et al., 1986; Krout et al., 2001).

Many midline thalamus neurons also exhibited a lowamplitude tonic excitation during the cue. However, unlike the phasic response, and also unlike tonic responses in thalamic sensory relay nuclei (Komura et al., 2001), this was greater in the unrewarded block. The opposing direction of reward modulation for phasic and tonic signaling presumably reflects distinct functional correlates and shows that single midline thalamus neurons are capable of multiplexing different types of information at different time scales, as described in other networks (BrombergMartin et al., 2010).

Midline thalamus has long been associated with vigilance functions (Van der Werf et al., 2002) and the apparently paradoxical opposite effects of reward association on phasic and tonic cue responses may be best conceptualized within this framework. In $\mathrm{C} \rightarrow \mathrm{R}$ trials, the cue has higher salience, which could contribute to the enhanced phasic cue response. In repeated acquisitionextinction situations such as used here, the arrival of reward on the first $\mathrm{C} \rightarrow \mathrm{R}$ trial is an important signal that that the contingency has changed and the cue should be attended to once more. Therefore, it is reasonable to imagine that some attentional resources would also be assigned to the end of the cue period on $\mathrm{C} \rightarrow \mathrm{X}$ trials. The low-amplitude tonic activity that we observed at this time could reflect this and, functionally, would increase background excitability and input-output gain in structures receiving midline thalamus inputs. This could optimize detection of the unexpected reward signal provided by DA inputs, which is known to be important for disrupting the latent inhibition of attention paid to familiar stimuli, allowing attention to be paid to previously irrelevant stimuli (Joseph et al., 2003) and thus enabling behavioral set shifting and renewed learning (Schultz et al., 1997; Schultz and Dickinson, 2000; Haluk and Floresco, 2009). Indeed, evidence from lesion studies suggests a key role in such set-shifting behavior for the nearby mediodorsal thalamic nucleus (Block et al., 2007), which receives some input from midline thalamic nuclei (Van der Werf et al., 2002).

The second category of response, in a partially overlapping set of neurons, was correlation with licking movements. There were three levels of complexity in these responses, summarized in Figure $8 B$. Activity simply associated with every lick (Fig. $8 B$, top) could reflect somatosensory inputs. However, this is unlikely because modulations were generally nearly simultaneous with licks. Instead, this activity may reflect the known connections of midline thalamus with striatum and motor cortex, which show similar activity (Murray and Sessle, 1992; Mittler et al., 1994). Nevertheless, many of these neurons also showed cue responses, supporting hypotheses proposing sensorimotor integration functions for midline thalamus (Van der Werf et al., 2002).

Of particular interest were neurons with responses that were selective for the first postsolenoid lick. This pattern could be achieved if information about the timing of licks were combined with information about the occurrence of solenoid activation in a logical "and" function (Fig. 8B, middle). Because solenoid activation indicates reward availability, these neurons could signal to downstream structures the time of the particular lick expected from prior learning to deliver reward. Such signals are important for the maintenance of forward associations between events and subsequent rewards; that is, assigning incentive salience (Kelley et al., 2005; Haight and Flagel, 2014) or "temporal credit" (Sutton, 1988; Daw et al., 2006) to cues as reward predictors.

Most of the neurons with responses to the first postsolenoid lick showed even more refined selectivity in that the response depended on whether there was previously established licking on the trial. Interestingly, these responses appeared to become more prominent at deeper locations possibly corresponding to ventral group nuclei. This response profile fits the hypothesis of van der Werf et al. (2002), who proposed, based on connectivity, that these nuclei may have "higher-order" cognitive-motor roles.

Most highly selective neurons responded more strongly if the first postsolenoid lick was within a previously established sequence. Neurons responding preferentially to specific movements within sequences occur in striatal and cortical regions (Aldridge and Berridge, 1998; Shidara et al., 1998; Shima and Tanji, 2000). These have been proposed to provide different signals depending on the task. When sequences must be completed before obtaining reward, they have been hypothesized to provide a "keep going" signal (Shidara et al., 1998), whereas when chains of movements at different joints are required, they code the temporal ordering of the movements (Aldridge and Berridge, 1998; Shima and Tanji, 2000). The within-sequence response that we observed here occurred at the onset of reward delivery so was not a keep-going signal, and was also not related to the order of a lick within the sequence. Rather, it coded the time of whichever lick in a sequence followed an external event, solenoid activation, and was also gated according to whether a licking action pattern had been triggered by the cue (Fig. $8 B$, bottom). This multifactorial signal could provide feedback that the initiation of licking was an appropriate response to the cue. Such signals are necessary for reinforcing conditioned behavioral responses and learning action-outcome linkages. These functions have been discussed extensively in relation to basal ganglia and cortical processing, with thalamic nuclei serving as simple relays (Houk, 2001; Aggarwal et al., 2012; Bermudez and Schultz, 2014). The discovery of more complex responses suggests that midline thalamus also integrates multiple types of information to contribute actively to these computations.

\section{References}

Aggarwal M, Hyland BI, Wickens JR (2012) Neural control of dopamine neurotransmission: implications for reinforcement learning. Eur J Neurosci 35:1115-1123. CrossRef Medline

Aldridge JW, Berridge KC (1998) Coding of serial order by neostriatal neurons: a 'natural action' approach to movement sequence. J Neurosci 18 : 2777-2787. Medline

Bermudez MA, Schultz W (2014) Timing in reward and decision processes. Philos Trans R Soc Lond B Biol Sci 369:20120468. CrossRef Medline

Block AE, Dhanji H, Thompson-Tardif SF, Floresco SB (2007) Thalamicprefrontal cortical-ventral striatal circuitry mediates dissociable components of strategy set shifting. Cereb Cortex 17:1625-1636. CrossRef Medline

Brecht M, Goebel R, Singer W, Engel AK (2001) Synchronization of visual responses in the superior colliculus of awake cats. Neuroreport 12:43-47. CrossRef Medline

Bromberg-Martin ES, Matsumoto M, Hikosaka O (2010) Distinct tonic and phasic anticipatory activity in lateral habenula and dopamine neurons. Neuron 67:144-155. CrossRef Medline

Brown EE, Robertson GS, Fibiger HC (1992) Evidence for conditional neuronal activation following exposure to a cocaine-paired environment: role of forebrain limbic structures. J Neurosci 12:4112-4121. Medline

Comoli E, Coizet V, Boyes J, Bolam JP, Canteras NS, Quirk RH, Overton PG, 
Redgrave P (2003) A direct projection from superior colliculus to substantia nigra for detecting salient visual events. Nat Neurosci 6:974-980. CrossRef Medline

Corbit JD, Luschei ES (1969) Invariance of the rat's rate of drinking. J Comp Physiol Psychol 69:119-125. CrossRef Medline

Daw ND, Courville AC, Touretzky DS (2006) Representation and timing in theories of the dopamine system. Neural Comput 18:1637-1677. CrossRef Medline

Dommett E, Coizet V, Blaha CD, Martindale J, Lefebvre V, Walton N, Mayhew JE, Overton PG, Redgrave P (2005) How visual stimuli activate dopaminergic neurons at short latency. Science 307:1476-1479. CrossRef Medline

Flagel SB, Cameron CM, Pickup KN, Watson SJ, Akil H, Robinson TE (2011) A food predictive cue must be attributed with incentive salience for it to induce c-fos mRNA expression in cortico-striatal-thalamic brain regions. Neuroscience 196:80-96. CrossRef Medline

Groenewegen HJ, Berendse HW (1994) The specificity of the 'nonspecific' midline and intralaminar thalamic nuclei. Trends Neurosci 17:52-57. CrossRef Medline

Haight JL, Flagel SB (2014) A potential role for the paraventricular nucleus of the thalamus in mediating individual variation in Pavlovian conditioned responses. Front Behav Neurosci 8:79. Medline

Haluk DM, Floresco SB (2009) Ventral striatal dopamine modulation of different forms of behavioral flexibility. Neuropsychopharmacology 34 : 2041-2052. CrossRef Medline

Houk JC (2001) Neurophysiology of frontal-subcortical loops. In: Frontalsubcortical circuits in psychiatric and neurological disorders (Lichter DG, Cummings JL, eds). New York: Guilford.

Hsu DT, Kirouac GJ, Zubieta JK, Bhatnagar S (2014) Contributions of the paraventricular thalamic nucleus in the regulation of stress, motivation, and mood. Front Behav Neurosci 8:73. Medline

Igelstrom KM, Herbison AE, Hyland BI (2010) Enhanced c-Fos expression in superior colliculus, paraventricular thalamus and septum during learning of cue-reward association. Neuroscience 168:706-714. CrossRef Medline

Ikeda T, Hikosaka O (2007) Positive and negative modulation of motor response in primate superior colliculus by reward expectation. J Neurophysiol 98:3163-3170. CrossRef Medline

Jones MW, Kilpatrick IC, Phillipson OT (1989) Regulation of dopamine function in the nucleus accumbens of the rat by the thalamic paraventricular nucleus and adjacent midline nuclei. Exp Brain Res 76:572-580. CrossRef Medline

Joseph MH, Datla K, Young AM (2003) The interpretation of the measurement of nucleus accumbens dopamine by in vivo dialysis: the kick, the craving or the cognition? Neurosci Biobehav Rev 27:527-541. CrossRef Medline

Kelley AE, Baldo BA, Pratt WE (2005) A proposed hypothalamic-thalamicstriatal axis for the integration of energy balance, arousal, and food reward. J Comp Neurol 493:72-85. CrossRef Medline

Komura Y, Tamura R, Uwano T, Nishijo H, Kaga K, Ono T (2001) Retrospective and prospective coding for predicted reward in the sensory thalamus. Nature 412:546-549. CrossRef Medline

Krout KE, Loewy AD (2000a) Periaqueductal gray matter projections to midline and intralaminar thalamic nuclei of the rat. J Comp Neurol 424: 111-141. CrossRef Medline

Krout KE, Loewy AD (2000b) Parabrachial nucleus projections to midline and intralaminar thalamic nuclei of the rat. J Comp Neurol 428:475-494. CrossRef Medline

Krout KE, Loewy AD, Westby GW, Redgrave P (2001) Superior colliculus projections to midline and intralaminar thalamic nuclei of the rat. J Comp Neurol 431:198-216. CrossRef Medline

Krout KE, Belzer RE, Loewy AD (2002) Brainstem projections to midline and intralaminar thalamic nuclei of the rat. J Comp Neurol 448:53-101. CrossRef Medline
Li Y, Dalphin N, Hyland BI (2013) Association with reward negatively modulates short latency phasic conditioned responses of dorsal raphe nucleus neurons in freely moving rats. J Neurosci 33:5065-5078. CrossRef Medline

Ligorio M, Descarries L, Warren RA (2009) Cholinergic innervation and thalamic input in rat nucleus accumbens. J Chem Neuroanat 37:33-45. CrossRef Medline

Lo FS, Cork RJ, Mize RR (1998) Physiological properties of neurons in the optic layer of the rat's superior colliculus. J Neurophysiol 80:331-343. Medline

Matsumoto N, Minamimoto T, Graybiel AM, Kimura M (2001) Neurons in the thalamic CM-Pf complex supply striatal neurons with information about behaviorally significant sensory events. J Neurophysiol 85: 960-976. Medline

Mittler T, Cho J, Peoples LL, West MO (1994) Representation of the body in the lateral striatum of the freely moving rat: single neurons related to licking. Exp Brain Res 98:163-167. Medline

Murray GM, Sessle BJ (1992) Functional properties of single neurons in the face primary motor cortex of the primate. II. Relations with trained orofacial motor behavior. J Neurophysiol 67:759-774. Medline

Pan WX, Hyland BI (2005) Pedunculopontine tegmental nucleus controls conditioned responses of midbrain dopamine neurons in behaving rats. J Neurosci 25:4725-4732. CrossRef Medline

Pan WX, Schmidt R, Wickens JR, Hyland BI (2005) Dopamine cells respond to predicted events during classical conditioning: evidence for eligibility traces in the reward-learning network. J Neurosci 25:6235-6242. CrossRef Medline

Parsons MP, Li S, Kirouac GJ (2006) The paraventricular nucleus of the thalamus as an interface between the orexin and CART peptides and the shell of the nucleus accumbens. Synapse 59:480-490. CrossRef Medline

Parsons MP, Li S, Kirouac GJ (2007) Functional and anatomical connection between the paraventricular nucleus of the thalamus and dopamine fibers of the nucleus accumbens. J Comp Neurol 500:1050-1063. CrossRef Medline

Paxinos G, Watson C (2007) The rat brain in stereotaxic coordinates, Ed 6. Amsterdam: Elsevier.

Pinto A, Jankowski M, Sesack SR (2003) Projections from the paraventricular nucleus of the thalamus to the rat prefrontal cortex and nucleus accumbens shell: ultrastructural characteristics and spatial relationships with dopamine afferents. J Comp Neurol 459:142-155. CrossRef Medline

Schultz W (1998) Predictive reward signal of dopamine neurons. J Neurophysiol 80:1-27. Medline

Schultz W (2002) Getting formal with dopamine and reward. Neuron 36: 241-263. CrossRef Medline

Schultz W, Dickinson A (2000) Neuronal coding of prediction errors. Annu Rev Neurosci 23:473-500. CrossRef Medline

Schultz W, Dayan P, Montague PR (1997) A neural substrate of prediction and reward. Science 275:1593-1599. CrossRef Medline

Shidara M, Aigner TG, Richmond BJ (1998) Neuronal signals in the monkey ventral striatum related to progress through a predictable series of trials. J Neurosci 18:2613-2625. Medline

Shima K, Tanji J (2000) Neuronal activity in the supplementary and presupplementary motor areas for temporal organization of multiple movements. J Neurophysiol 84:2148-2160. Medline

Sutton RS (1988) Learning to predict by the methods of temporal differences. Mach Learn 3:9-44.

Van der Werf YD, Witter MP, Groenewegen HJ (2002) The intralaminar and midline nuclei of the thalamus: anatomical and functional evidence for participation in processes of arousal and awareness. Brain Res Brain Res Rev 39:107-140. CrossRef Medline

Yamasaki DS, Krauthamer GM, Rhoades RW (1986) Superior collicular projection to intralaminar thalamus in rat. Brain Res 378:223-233. CrossRef Medline 